\title{
Simple Method for Preparing Glucose Biosensor Based on Glucose Oxidase in Nanocomposite Material of Single-Wall Carbon Nanotubes/Ionic Liquid
}

\author{
Weina Wang, Guang Yin, Xiuju Ma, Jun Wan* \\ College of Environment and Safety Engineering, Qingdao University of Science and Technology, Qingdao, China. \\ Email: "wanjundz@sohu.com
}

Received March $1^{\text {st }}, 2012$; revised March 21 ${ }^{\text {st }}, 2012$; accepted April $9^{\text {th }}, 2012$

\begin{abstract}
Based on electric conductivity and wide potential window of ionic liquid (IL) and electric property of single-wall carbon nanotubes (SWCNTs), composite material of IL-SWCNTs was prepared, glucose sensor was built with this material for immobilizing glucose oxidase (GOx). It showed good response, sensitivity and stability for long time for glucose detection. Linear range for the detection of glucose was from $0.5 \times 10^{-6} \mathrm{M}$ to $12 \times 10^{-6} \mathrm{M}$ while detection limit was $6.26 \times 10^{-8} \mathrm{M}(\mathrm{S} / \mathrm{N}=3)$.
\end{abstract}

Keywords: Biosensor; Glucose Oxidase; Single-Wall Carbon Nanotubes; Ionic Liquid; Glucose

\section{Introduction}

Single-walled carbon nanotubes (SWCNTs) and ionic liquids (ILs) have attracted researchers' interest recently. SWCNTs are of significant interest due to their unique properties and potential applications. The unique size distribution and hollow geometry of SWCNTs bestow upon them unique electronic, mechanical and chemical properties and potentially wide application. It has been reported that single-walled carbon nanotubes can be used to promote electron transfer reactions when used as an electrode material [1,2]. Ionic liquids (ILs) have good chemical and physical properties, such as good chemical and thermal stability, negligible vapour pressure, good electrical conductivity and a wide electrochemical window [3]. The use of electrodes prepared from carbon nanotubes and ILs have been reported in a number of articles. One way is to modify the surface of a glassy carbon electrode with a dispersion of CNTs/IL or CNTs /IL/polymer in a suitable solvent [4-7]. This kind of modified electrode provides a platform for fabrication of biosensors, which shows promising application to detect various biomacromolecules.

Glucose detection has important practical value in analysis of food and fermentation, the textile industry, environmental monitoring, medical diagnosis and other areas $[8,9]$. People have done a lot of effort focused on developing appropriate technology for accurate monitor-

\footnotetext{
${ }^{*}$ Corresponding author.
}

ing of glucose in the view of high sensitivity, high stability, high response rate, good selectivity and low production cost detection requirements. Now the main detection methods of glucose include surface plasmon resonance biosensor [10], near-infrared light biosensors [11], capacitive sensing [12], electrochemical luminescence [13], fluorescence detection [14], colorimetry [15], and current biosensors [16]. Among them, the current biosensor is a promising detection method because of its high sensitivity, miniaturization, compatibility, easy operation and low cost. Usually, enzyme-based glucose sensor is the use of glucose oxidase (GOx) to detect glucose.

In this paper, our approaches to development of new kinds of enzyme biosensor are essentially based on assembling glucose oxidase onto a SWCNTs-IL modified glassy carbon (GC) electrode by adsorption. Cyclic voltammetry and differential pulse voltammetry were used to investigate the electrochemical behaviors of GOx/Nafion/ SWCNTs-IL/GC electrode. By this method, the composite modified electrode exhibited its better electrocatalysis to glucose. The simple method provided an effective means for fabricating the novel biosensors.

\section{Experimental}

\subsection{Reagents and Apparatus}

Glucose oxidase (GOx, EC1.1.3.4,118 U·mg ${ }^{-1}$, Type II) purchased from Sigma and Aldrich. $\beta$ - $\mathrm{D}(+)$-glucose from Tokyo Kasei Kogyo Co., Ltd.(TCI). N,N-dimethyl for- 
mamide (DMF), from Tianjin Ruijinte Chemical Co., Ltd. The ionic liquid 1-Ethyl-3-methylimidazolium Bromide, from Songkong Chemical (HongKong) Co., Ltd. SWNTs (2.73 wt \% , - $\mathrm{COOH}$ ), from Chengdu Organic Chemicals Company Ltd. of Chinese Academy of Sciences. Nafion (5 wt\%) from Aldrich. 0.1 M PBS (containing $0.1 \mathrm{M} \mathrm{KCl}$ ) of various $\mathrm{pH}$ was prepared by mixing the stock solutions of $\mathrm{NaH}_{2} \mathrm{PO}_{4}$ and $\mathrm{Na}_{2} \mathrm{HPO}_{4}$. The solutions were deaerated with high purity nitrogen before the experiments and all of the electrochemical experiments were performed at an ambient temperature.

Electrochemical experiments were performed on a CHI 832B electrochemical analyzer (Shanghai Chenhua Instrument, China) with a three-electrode system comprising a modified GCE of diameter $4 \mathrm{~mm}$ as working electrode, a $\mathrm{Ag} / \mathrm{AgCl} /($ sat $\mathrm{KCl}$ ) electrode as reference electrode, and a platinum wire as auxiliary electrode.

\subsection{Preparation of the SWCNTs-IL/GCE}

Prior to use, the glassy carbon electrode was carefully polished with polishing paper and 1.0, 0.3 and $0.05 \mu \mathrm{m}$ alumina slurry, and sonicated respectively in water and ethanol for $2 \mathrm{~min}$. The electrode was rinsed in ethanol again and allowed to dry under the infrared light. An amount of $5.0 \mathrm{mg}$ of SWCNTs and $0.1911 \mathrm{mg}$ of ionic liquid were dispersed in $2 \mathrm{~mL}$ of N,N-Dimethylforma- mide (DMF) solution, then sonicated for 40 min with a uniformly dispersed solution obtained. A $5 \mu \mathrm{L}$ of the prepared suspension was dipped onto GC electrodes. After being dried under the infrared light, the SWCNTsIL modified GC electrodes were obtained.

\subsection{Preparation of GOx/Nafion/MWCNTs-IL/GCE}

The $2 \mathrm{mg} \cdot \mathrm{mL}^{-1} \mathrm{GOx}$ solution was prepared by dissolving GOx in 0.1 M PBS buffer (pH 7.0). The SWCNTs-ILmodified electrodes were immersed into the GOx solution for $24 \mathrm{~h}$ at $4^{\circ} \mathrm{C}$. A $5 \mu \mathrm{L}$ of Nafion $(1 \mathrm{wt} \%$ ) solution was dipped onto modified electrodes and dried at $4^{\circ} \mathrm{C}$. The modified electrode was stored at $4^{\circ} \mathrm{C}$ when not in use. Scheme 1 shows the preparation approach.

\section{Results and Discussion}

\subsection{Behavior of the SWCNTs-IL/GCE}

Figure 1 shows the $\mathrm{CV}$ of various electrodes in $2.5 \mathrm{mM}$ $\mathrm{K}_{3}\left[\mathrm{Fe}(\mathrm{CN})_{6}\right]$ containing $0.1 \mathrm{M} \mathrm{KCl}$ at $50 \mathrm{mV} \cdot \mathrm{s}^{-1}$. Bare GCE after coating with SWCNTs-IL, the current was substantially increased and still displayed a steady-state diffusion plateau. The synergistic effects can be ascribed to the excellent electron-transfer ability of SWCNTs and the ionic liquid.
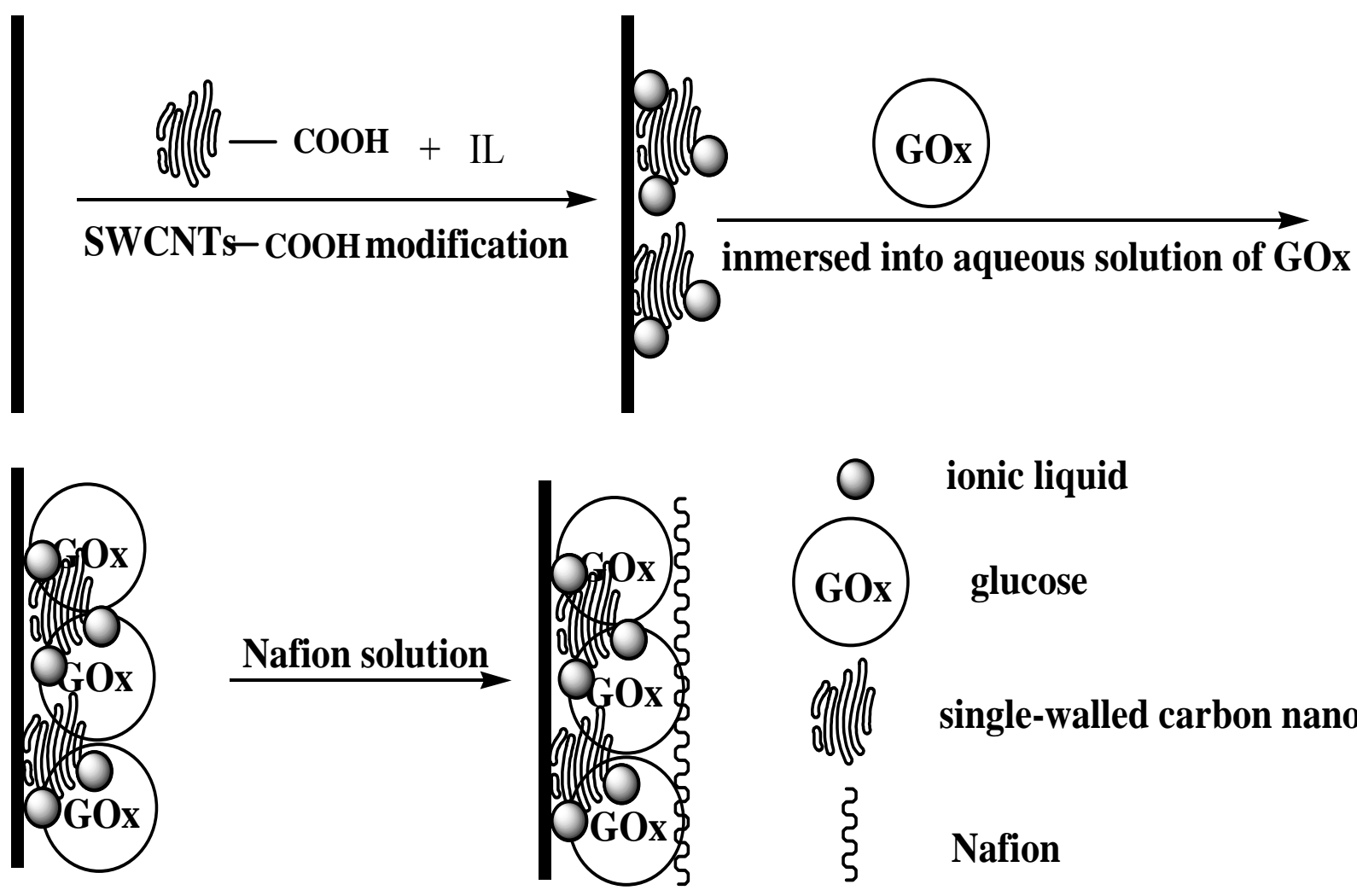

ionic liquid

glucose

single-walled carbon nanotube

Scheme 1. Preparing schematic diagram of modified GOx/Nafion/SWCNTs-IL/GCE. 


\subsection{Influence of the Scan Rate}

Typical CV curves of GOx/Nafion/SWCNTs-IL/GCE in 0.1 M PBS ( $\mathrm{pH} 7.0)$ at different scan rates are shown in Figure 2. A good linear relationship was found for the peak current and scan rate, with the results shown in Figure 2. The reduction and oxidation peak currents rise linearly with the linear regression equations as Ipc $(\mu \mathrm{A})$ $=9.624 \mathrm{v}^{1 / 2}(\mathrm{~V} / \mathrm{s})^{1 / 2}+0.1005(\mathrm{n}=8, \mathrm{r}=0.9986)$, Ipa $(\mu \mathrm{A})$ $=-12.23 \mathrm{v}^{1 / 2}(\mathrm{~V} / \mathrm{s})^{1 / 2}-0.4275(\mathrm{n}=8, \mathrm{r}=0.9978)$, respectively, suggesting that the reaction is a quasi-reversible diffusion-controlled process.

\subsection{Optimization Conditions for the Detection of Glucose}

Experiments were conducted to establish the effect of various parameters such as the concentration of room temperature ionic liquid, $\mathrm{pH}$, the concentration of SWCNTs on modified electrode performance.
In order to determine the optimal concentration of room temperature ionic liquid in SWCNTs suspension, we studied the influence of the temperature ionic liquid concentration range form $0.01 \mathrm{M}$ to $0.1 \mathrm{M}$ on the electrochemical characteristics of electrodes. Figure 3(a) shows the modified electrode displayed the best electrochemical properties when the concentration of IL in SWCNTs suspension is $0.05 \mathrm{M}$.

Figure 3(b) shows the i-pH curves obtained by the CV curves of GOx/Nafion/SWCNTs-IL/GC electrode in 0.1 $\mathrm{M}$ PB solution with different $\mathrm{pH}$ at a scan rate of 50 $\mathrm{mV} \cdot \mathrm{s}^{-1}$ when the concentration of glucose oxidase was 1 $\mathrm{mM}$. As shown in Figure 3(b), when the $\mathrm{pH}$ value of 0.1 $\mathrm{M}$ PB solution is 7.0, the redox peaks current ratio is about 1 , the peak potential diference is the smallest, reversibility is the best. Therefore, $\mathrm{pH} 7.0$ was chosen as the optimum value in the following experiments. All the experiments were carried out at $\mathrm{pH} 7.0$ unless specially stated.

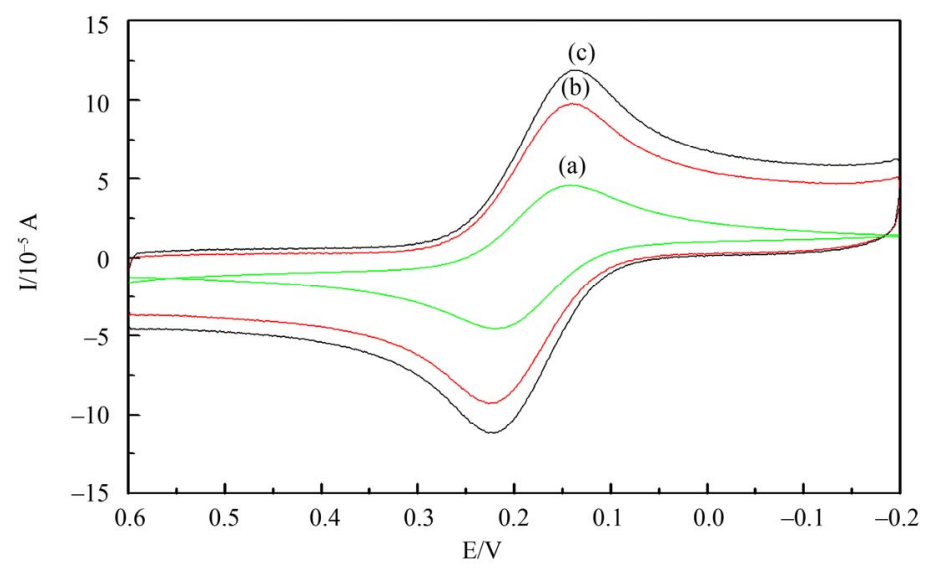

Figure 1. Cyclic voltammetry obtained with a GCE (a) SWCNTs/GCE (b) and SWCNTs-IL/GCE (c) in 0.1 M KCl solution containing $2.5 \mathrm{mM} \mathrm{K} \mathrm{K}_{3} \mathrm{Fe}(\mathrm{CN})_{6}$ at a scan rate of $50 \mathrm{mV} \cdot \mathrm{s}^{-1}$.

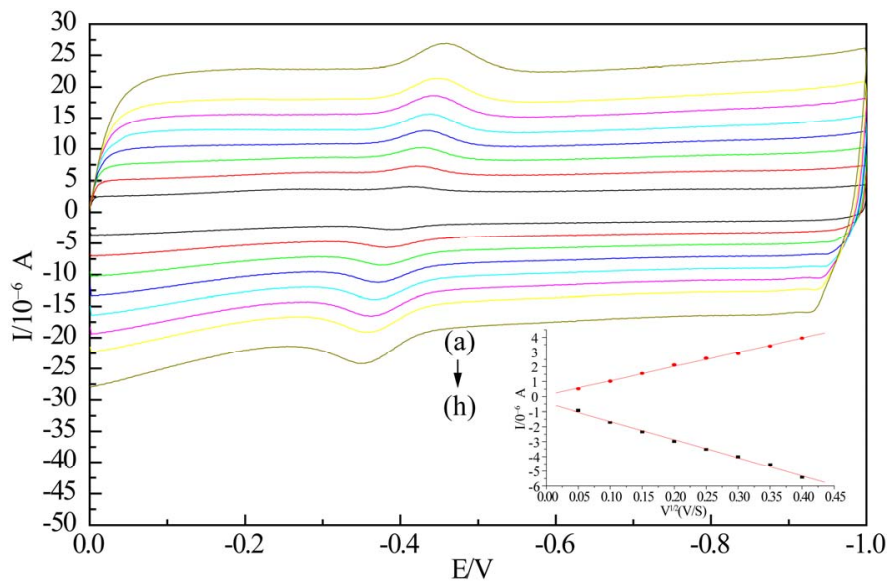

Figure 2. Typical CV curves of GOx/Nafion/SWCNTs-IL/GCE in $0.1 \mathrm{M}$ PB solution (pH 7.0) at different scan rates (V·s $\mathrm{s}^{-1}$ ): (a) $0.05 \mathrm{~V} \cdot \mathrm{s}^{-1}$; (b) $0.1 \mathrm{~V} \cdot \mathrm{s}^{-1}$; (c) $0.15 \mathrm{~V} \cdot \mathrm{s}^{-1}$; (d) $0.2 \mathrm{~V} \cdot \mathrm{s}^{-1}$; (e) $0.25 \mathrm{~V} \cdot \mathrm{s}^{-1}$; (f) $0.3 \mathrm{~V} \cdot \mathrm{s}^{-1}$; (g) $0.35 \mathrm{~V} \cdot \mathrm{s}^{-1}$; (h) $0.4 \mathrm{~V} \cdot \mathrm{s}^{-1}$. Inset shows a calibration plot of peak current versus scan rate. 


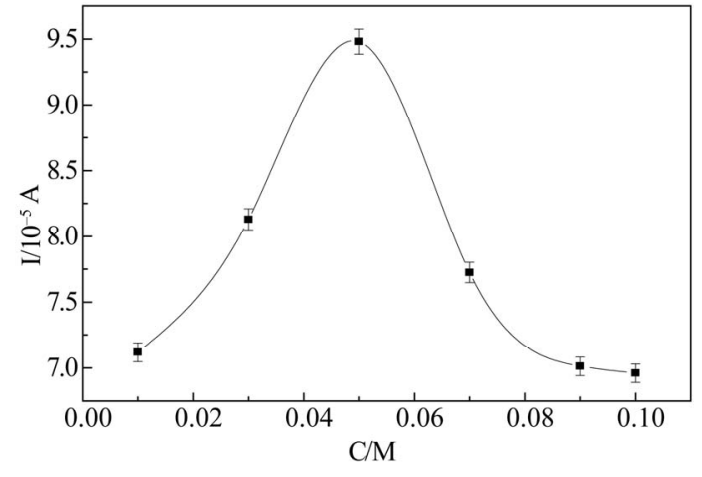

(a)

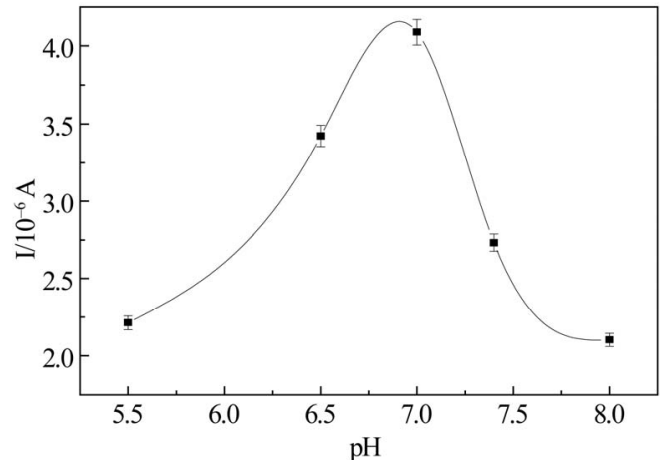

(b)

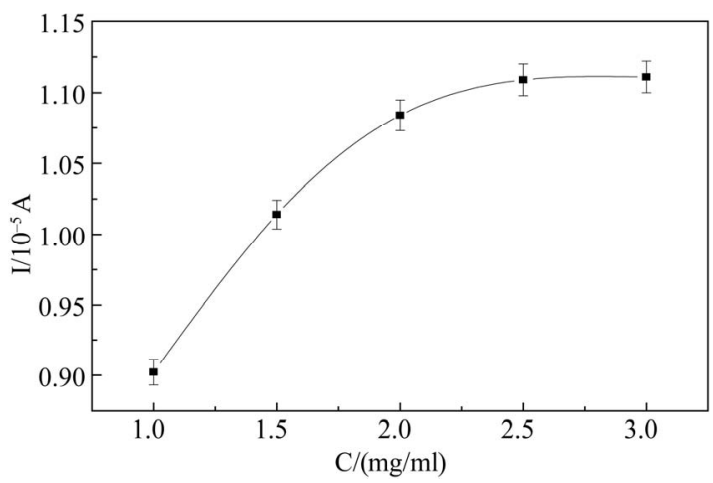

(c)

Figure 3. (a) Different concentration of room temperature ionic liquid in $0.1 \mathrm{M} \mathrm{KCl}$ solution containing $2.5 \mathrm{mM} \mathrm{K}_{3} \mathrm{Fe}(\mathrm{CN})_{6}$. Error bars represent device-to-device standard deviation $(\mathbf{n}=3)$; (b) I-pH curves obtained by the CV curves of GOx/ Nafion/SWCNTs-IL/GC electrode in $0.1 \mathrm{M} \mathrm{PB}$ solution with different $\mathrm{pH}$ at a scan rate of $50 \mathrm{mV} \cdot \mathrm{s}^{-1}$ when the concentration of glucose oxidase was $1 \mathrm{mM}$. Error bars represent device-to-device standard deviation (n = 3); (c) Different concentration of SWCNTs in $0.1 \mathrm{M} \mathrm{KCl}$ solution containing $2.5 \mathrm{mM} \mathrm{K}_{3} \mathrm{Fe}(\mathrm{CN})_{6}$. Error bars represent device-to-device standard deviation $(\mathrm{n}=3)$.

The concentration of SWCNTs impacts the concentration of glucose oxidase's adsorption. In this paper, we studied the influence of the SWCNTs concentration range form $1.0 \mathrm{mg} \cdot \mathrm{mL}^{-1}$ to $3.0 \mathrm{mg} \cdot \mathrm{mL}^{-1}$ on the electrochemical characteristics of electrodes when the concentration of IL in suspension was 0.05 M. As shown in Figure 3(c), with the increase of the concentration of SWCNTs, the content of glucose oxidase's adsorption increased. When the concentration of SWCNTs was 2.5 $\mathrm{mg} \cdot \mathrm{mL}^{-1}$, increased the concentration, the curve tended to a horizontal line. The concentration of $2.5 \mathrm{mg} \cdot \mathrm{mL}^{-1}$ SWCNTs was chosen as the optimal concentration for all experiments.

\subsection{Stability Investigation of GOx/Nafion/SWCNTs-IL/GCE}

As shown in Figure 4, the long-term storage stability of GOx/Nafion/SWCNTs-IL/GC electrode was studied over a certain period of time by monitoring the $\mathrm{CV}$ currents in 0.1 M PB solution ( $\mathrm{pH}$ 7.0). When the modified electrode was stored at $4^{\circ} \mathrm{C}$ for several days, the electrode sensitivity to glucose decreased gradually, but the reduc- tion rate is relatively small, the modified electrode shows good stability. The better long-term stability could be attributed to SWCNTs and IL entrapped in the film providing desirable microenvironment for glucose oxidase immobilization. All the results indicated that the composite electrode had better stability.

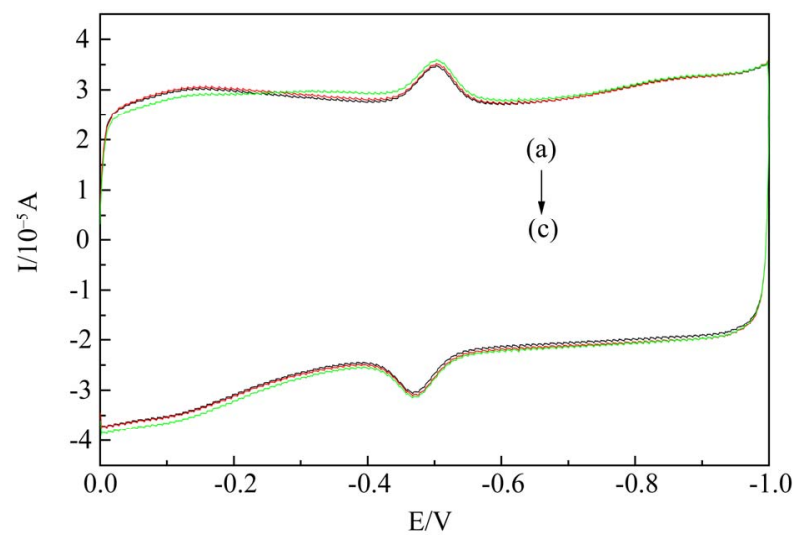

Figure 4. Typical CV curves of GOx/Nafion/ SWCNTs-IL/ GCE in 0.1 M PB solution (pH 7.0) at different time: (a) initialization; (b) $7 \mathrm{~d}$; (c) $14 \mathrm{~d}$. 


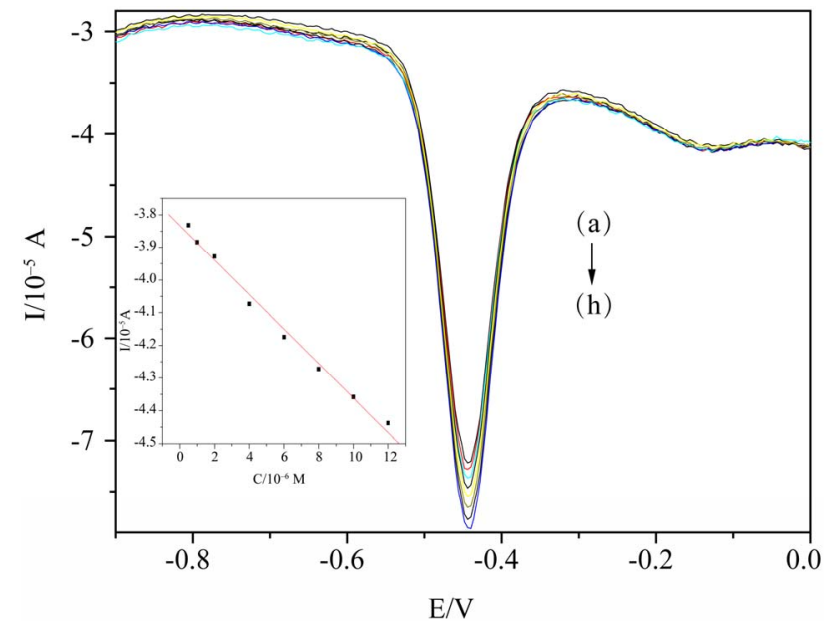

Figure 5. Differential pulse voltammetry curves obtained with different concentration of glucose in $0.1 \mathrm{M}$ PB solution of GOx/Nafion/SWCNTs-IL/GCE: (a) $0.5 \times 10^{-7} \mathrm{M}$; (b) 1.0 $\times 10^{-6} \mathrm{M}$; (c) $2.0 \times 10^{-6} \mathrm{M}$; (d) $4.0 \times 10^{-6} \mathrm{M}$; (e) $6.0 \times 10^{-6} \mathrm{M}$; (f) $8.0 \times 10^{-6} \mathrm{M}$; (g) $1.0 \times 10^{-5} \mathrm{M}$; (h) $1.2 \times 10^{-5} \mathrm{M}$. The inset shows the plot of catalytic oxidation peak current versus the concentration of glucose.

\subsection{Electrochemical Detection of Glucose}

In order to examine the applicability of $\mathrm{GOx} / \mathrm{Nafion}$ /SWCNTs-IL/GCE, differential pulse voltammetry method was used for glucose detection. The differential pulse voltammetry curves were obtained under the optimal conditions shown in Figure 5. With the increasing glucose concentration, the peak current of the modified electrode increased linearly. The linear response range to glucose concentration was from $0.5 \times 10^{-6} \mathrm{M}$ to $12 \times 10^{-6}$ $\mathrm{M}$ and linear regression equation was $\mathrm{I}\left(10^{-5} \mathrm{~A}\right)=$ $-0.05279 \mathrm{C}\left(10^{-7} \mathrm{M}\right)-3.8333(\mathrm{n}=8, \mathrm{r}=0.995)$ with a detection limit of $6.26 \times 10^{-8} \mathrm{M}$ at $3 \sigma$. The results indicated that glucose oxidase in Nafion/SWCNTs-IR/GCE had a higher sensitivity to glucose.

\section{Conclusion}

With immobilization of glucose oxidase at the surface of SWCNTs/IL modified GC electrode a simple and promising sensor for glucose detection was demonstrated. The modified electrodes display more excellent electrochemical characteristics, long-term stability, high sensitivity and much lower detection limits. The composite material based on single-walled carbon nanotubes and ionic liquid can find wide potential applications in direct electrochemistry, biosensors and biocatalysts.

\section{REFERENCES}

[1] J. Wang, "Carbon-Nanotube Based Electrochemical Bio- sensors: A Review," Electroanalysis, Vol. 17, No. 1, 2005, pp. 7-14. doi:10.1002/elan.200403113

[2] J. Wang, M. Musameh and Y. H. Lin, "Solubilization of Carbon Nanotubes by Nafion toward the Preparation of Amperometric Biosensors," Journal of the American Chemical Society, Vol. 125, No. 9, 2003, pp. 2408-2409. doi:10.1021/ja028951v

[3] W. H. Lo, H. Y. Yang and G. T. Wei, "One-Pot Desulfurization of Light Oils by Chemical Oxidation and Solvent Extraction with Room Temperature Ionic Liquids," Green Chemistry, Vol. 5, 2003, p. 639. doi:10.1039/b305993f

[4] Q. Wang, H. Tang, Q. Xie, L. Tan, Y. Zhang, B. Li and S. Yao, "Room-Temperature Ionic Liquids/Multi-Walled Carbon Nanotubes/Chitosan Composite Electrode for Electrochemical Analysis of NADH," Electrochimca Acta, Vol. 52, No. 24, 2007, pp. 6630-6637. doi:10.1016/j.electacta.2007.04.057

[5] F. Xiao, F. Zhao, J. Li, R. Yan, J. Yu and B. Zeng, "Sensitive Voltammetric Determination of Chloramphenicol by Using Single-Wall Carbon Nanotube-Gold Nanoparticle-Ionic Liquid Composite Film Modified Glassy Carbon Electrodes," Analytica Chimica Acta, Vol. 596, 2007, pp. 79-85. doi:10.1016/j.aca.2007.05.053

[6] Y. Liu, L. Huang and S. Dong, "Electrochemical Catalysis and Thermal Stability Characterization of LaccaseCarbon Nanotubes-Ionic Liquid Nanocomposite Modified Graphite Electrode," Biosensors and Bioelectronics, Vol. 23, No. 1, 2007, pp. 35-41. doi:10.1016/i.bios.2007.03.009

[7] Q. Zhao, D. Zhan, H. Ma, M. Zhang, Y. Zhao, P. Jing, Z. Zhu, X. Wan, Y. Shao and Q. Zhuang, "Direct Proteins Electrochemistry Based on Ionic Liquid Mediated Carbon Nanotube Modified Glassy Carbon Electrode," Frontiers in Bioscience, Vol. 10, No. 1, 2005, pp. 326-334. doi: $10.2741 / 1530$

[8] S. R. Lee, Y. T. Lee, K. Sawada, H. Takao and M. Ishida, "Development of a Disposable Glucose Biosensor Using Electroless-Plated $\mathrm{Au} / \mathrm{Ni} / \mathrm{Copper}$ Low Electrical Resistance Electrodes," Biosensors and Bioelectronics, Vol. 24, No. 3, 2008, pp. 410-414. doi:10.1016/j.bios.2008.04.017

[9] J. D. Newman and A. P. Turner, "Home Blood Glucose Biosensors: A Commercial Perspective," Biosensors and Bioelectronics, Vol. 20, No. 12, 2005, pp. 2435-2453. doi:10.1016/j.bios.2004.11.012

[10] X. W. Shen, C. Z. Huang and Y. F. Li, "Localized Surface Plasmon Resonance Sensing Detection of Glucose in the Serum Samples of Diabetes Sufferers Based on the Redox Reaction of Chlorauric Acid," Talanta, Vol. 72, No. 4, 2007, pp. 1432-1437. doi:10.1016/j.talanta.2007.01.066

[11] C. Song, P. E. Pehrsson and W. Zhao, "Optical Enzymatic Detection of Glucose Based on Hydrogen PeroxideSensitive HiPco Carbon Nanotubes," Journal of Materials Research, Vol. 21, No. 11, 2006, pp. 2817-2823. doi:10.1557/jmr.2006.0343

[12] Z. Cheng, E. Wang and X. Yang, "Capacitive Detection of Glucose Using Molecularly Imprinted Polymers," Biosensors and Bioelectronics, Vol. 16, No. 3, 2001, pp. 
179-185. doi:10.1016/S0956-5663(01)00137-3

[13] J. Kremeskotter, R. Wilson and D. J. Schiffrin, "Detection of Glucose via Electrochemilumine-Science in a Thin-Layer Cell with a Planar Optical Waveguide," Measurement Science and Technology, Vol. 6, No. 9, 1995, pp. 1325-1328. doi:10.1088/0957-0233/6/9/012

[14] P. W. Barone, R. S. Parker and M. S. Strano, "In Vivo Fluorescence Detection of Glucose Using a SingleWalled Carbon Nanotube Optical Sensor: Design, Fluorophore Properties, Advantages, and Disadvantages," Analytical Chemistry, Vol. 77, No. 23, 2005, pp. 7556-7562. doi:10.1021/ac0511997

[15] M. Morikawa, N. Kimizuka, M. Yoshihara and T. Endo, "New Colorimetric Detection of Glucose by Means of
Electronaccepting Indicators: Ligand Substitution of $\left[\mathrm{Fe}(\mathrm{acac})_{3-\mathrm{n}}(\mathrm{phen})_{\mathrm{n}}\right]^{\mathrm{n}+}$ Complexes Triggered by Electron Transfer from Glucose Oxidase," Chemistry-A European Journal, Vol. 8, No. 24, 2002, pp. 5580-5584. doi:10.1002/1521-3765(20021216)8:24<5580::AID-CHE $\mathrm{M} 5580>3.0 . \mathrm{CO} ; 2-\mathrm{V}$

[16] P. Du, B. Zhou and C. X. Cai, "Development of an Amperometric Biosensor for Glucose Based on Electrocatalytic Reduction of Hydrogen Peroxide at the SingleWalled Carbon Nanotube/Nile Blue A Nanocomposite Modified Electrode," Electroanalytical Chemistry, Vol. 614, No. 1-2, 2008, pp. 149-156. doi:10.1016/i.jelechem.2007.11.036 